\title{
Delta-x Nomenclature
}

National Cancer Institute

\section{Source}

National Cancer Institute. delta-x Nomenclature. NCI Thesaurus. Code C88199.

A convention for representing the molecular structure of fatty acids where each double bond is represented by the symbol delta with an exponent of $x$ that indicates the $x$ th carbon-carbon bond as counted from the carboxylic end. Each double bond is also preceded by an indication of the conformation as either cis or trans. 